\title{
Sleep Quality of Students from Elementary School to University: A Cross-Sectional Study
}

This article was published in the following Dove Press journal:

Nature and Science of Sleep

\author{
Baohua Liu ${ }^{1,2, *}$ \\ Fei $\mathrm{Gao}^{3, *}$ \\ Jianfeng Zhang ${ }^{3, *}$ \\ Hongguo Zhou' \\ Ning Sun' \\ Laiyou $\mathrm{Li}^{\prime}$ \\ Libo Liang ${ }^{2}$ \\ Ning Ning ${ }^{2}$ \\ Qunhong $\mathrm{Wu}^{2}$ \\ Miaomiao Zhao ${ }^{4}$ \\ 'School of Health Services and \\ Management, Ningbo College of Health \\ Sciences, Ningbo 315100, Zhejiang, \\ People's Republic of China; ${ }^{2}$ Department \\ of Social Medicine, School of Health \\ Management, Harbin Medical University, \\ Harbin 15008I, Heilongjiang, People's \\ Republic of China; ${ }^{3}$ Institute of Food \\ Safety and School Health, Heilongjiang \\ Center for Disease Control and \\ Prevention, Harbin 150030, Heilongjiang, \\ People's Republic of China; ${ }^{4}$ Department \\ of Health Management, School of Public \\ Health, Nantong University, Nantong \\ 2260 I9, Jiangsu, People's Republic of \\ China
}

*These authors contributed equally to this work
Background: Sleep affects a wide array of health outcomes and is associated with the quality of life. Among students, sleep quality is affected by school stage and grade; however, data regarding the different sleep-related problems students experience at different school stages are limited. In this study, we aimed to explore sleep quality among a student sample ranging from elementary school to university level.

Methods: Overall, data were examined for 9392 subjects aged 9-22 years. Information on sociodemographic characteristics and other variables were collected through selfadministered questionnaires. Sleep quality on school nights was evaluated using the standard Pittsburgh Sleep Quality Index; global score $>5$ was classified as poor sleep quality. For the high school sample, logistic regression analysis was used to estimate associations between sleep quality and certain factors.

Results: Of the elementary school, middle school, vocational high school, senior high school, and university students, $7.5 \%, 19.2 \%, 28.6 \%, 41.9 \%$, and $28.5 \%$, respectively, showed poor sleep quality. The high school students reported the highest prevalence of shorter sleep duration (70.8\%), day dysfunction (84.7\%), and subjective poor sleep quality $(17.2 \%)$. The elementary school students showed the highest prevalence of poor sleep efficiency $(17.9 \%)$. The university students showed the highest prevalence of sleep medication use $(6.4 \%)$. The vocational high school students reported the highest prevalence of sleep latency $(6.3 \%)$ and sleep disturbance $(7.4 \%)$. Logistic regression modeling indicated that sleep quality is positively associated with school stage, grade, family atmosphere, academic pressure, and number of friends.

Conclusion: Sleep quality and sleep features change greatly from elementary school to university. Interventions to improve sleep quality should consider targeting the specific issues students experience at each school stage. Alarmed by the high prevalence of poor sleep quality among high school students, it is recommended that high school students should be informed of their sleep matter and the consequences.

Keywords: different school stages, sleep quality, students, PSQI

\section{Introduction}

Sleep quality has implications for psychosocial, behavioral, and health issues, as well as health-related quality of life; thus, it represents a major public health concern. As an indispensable component of life, sleep plays a major role in health and growth; many significant physiological functions and brain activities occur during sleep, such as the relieving of fatigue and brain development in early childhood. ${ }^{1}$ Suboptimal sleep quality is associated with a wide range of diseases and adverse health outcomes, both physical and mental. ${ }^{2-7}$
Correspondence: Qunhong Wu;

Miaomiao Zhao

Tel +86I8686825192;

$+86 \mid 8860979901$

Email wuqunhong@163.com;

zhaomiaomiao0201@163.com
Nature and Science of Sleep 2020:12 855-864 
Sleep patterns change throughout life ${ }^{8}$ and are influenced by a variety of internal and external factors, which are extremely complicated and difficult to fully identify and explain. The entire school period (ranging from elementary school to university) represents a critical stage of human life and plays a very important role in students' physiological development and the establishment of values and self-cognition. However, this is also a period of vulnerability that can be accompanied by emotional and behavioral distress. During all of these school stages, students experience continuous changes in their physical functions, psychology, behaviors, cognition, and learning objectives, all of which have a substantial effect on their sleep quality. The effects of sleep problems on students have been widely reported. Unhealthy sleep patterns and sleep disturbances are common across students from a wide range of areas and cultures and are associated with a host of mental, physical, cognitive, and academic consequences. $^{9-11}$ Insufficient sleep is highly prevalent among elementary school students and, for these students, is associated with an increased risk of obesity, behavioral problems, and poor academic performance. ${ }^{12,13}$ Despite this, many studies have reported that adolescent students experience a higher incidence of sleep problems and shorter sleep durations. For example, a meta-analysis of the sleep patterns of adolescents worldwide found that approximately $45 \%$ of adolescents in grades 6 to 12 were affected by insufficient sleep. ${ }^{14}$ Chronic exposure to lowquality sleep among adolescent students is related to overweight, poor self-rated health, depression symptoms, and poor well-being, ${ }^{10,11}$ and can increase the risk of self-harm behavior and even suicide attempts. ${ }^{15}$ Meanwhile, regarding university students, unfavorable sleep status is usually closely associated with short sleep duration and negative impacts on social relationships. ${ }^{16,17}$ In particular, studies have found that sleep problems, such as sleep distress, onset insomnia, and lack of sleep are related to anxiety, depression, attention-deficit/hyperactivity disorder inattention, and suicidal ideation among college students. ${ }^{18,19}$

Given the high prevalence and heavy burden of poor sleep quality among students, identifying potentially modifiable factors so that can be targeted for the prevention or amelioration of sleep problems is an important research aim. Although the topic of students' sleep (or, at least, some aspects of it) is advancing at the international level, the effect of school stages (and related factors) on sleep has not been thoroughly analyzed. It is necessary to investigate sleep status at different school levels and to develop appropriate intervention methods (tailored to suit each school stage) to help students address sleep problems. Given that sleep quality and sleep problems vary greatly depending on age and population, ${ }^{20,21}$ and that following a large group of students over this long development period would present notable challenges, the central analyses of research into this topic should focused on comparing students at each of the five stages of schooling (elementary school, middle school, high school, vocational high school, and university), while sleep quality and factors related needs to be explored. In the present study, we explored sleep among a student sample ranging from elementary school to university, and this research represents one of the most extensive studies to examine the sleep quality of Chinese students. Such descriptive baseline data can obtain an objective perspective of the potential differences in the sleep patterns of students at different school stages, and provide evidence that can inform future efforts to improve the sleep status of students at each of these school stages.

\section{Materials and Methods}

\section{The Survey}

Data were collected from a cross-sectional questionnaire survey that was conducted from September to December 2018 in Heilongjiang Province, China, by the Heilongjiang Centre for Disease Control and Prevention. The survey aimed to monitor the prevalence of student behaviors that influence health. The questionnaire was reviewed and checked by a panel of public health experts and was revised after a pilot survey. The survey featured a series of items relating to habits, behaviors, cognition, and emotions. In the current study, responses to items regarding the quality of sleep and its related variables were explored.

A multi-stage cluster sampling method was adopted. Finally, four elementary schools, four middle schools, three high schools, one vocational high school and one university were randomly selected within each city (Harbin, Jiamusi, and Jixi) of Heilongjiang Province. A total of 9396 students participated in the survey; four questionnaires were discarded because important information was missing, resulting in a total of 9392 valid survey responses. The final sample comprised 2912 elementary school students from grades 4, 5 and 6, respectively; 2878 middle school students from grades 1, 2 and 3, respectively; 2160 high school students from grades 1, 2 and 3, respectively; 720 vocational high school students from grades $1,2,3$, respectively, and 722 college 
students from grades 1, 2 and 3, respectively. For each grade analyzed, identical numbers of classes were sampled from each participating school. Table 1 presents the characteristics of the sample and the variables investigated.

Data were collected through a self-administered questionnaire distributed in class; students completed the survey within 1 hour, while a well-trained member of the research group supervised according to instructions. All subjects were informed of the purpose of the study and were ensured that their identities would remain confidential. Students and their parents (the parents of the college students were not informed because these students had reached adulthood) provided written informed consent for participation in the study.

\section{Sleep Quality (Outcome)}

Quality of sleep was assessed using the Pittsburgh Sleep Quality Index (PSQI) scale. PSQI scale was used to measure the students' sleep characteristics for school nights over the past 1 month. The Chinese version of the PSQI has previously been determined to have good reliability and test-retest validity. ${ }^{22,23}$ It comprises 19 items and seven components: sleep duration, sleep efficiency, subjective sleep quality, sleep medication use, sleep latency, disturbances, and daytime dysfunction. The score range for each component is 0 to 3 . The total score is determined by summing the scores for each component, and consequently ranges from 0 to 21 . Good sleep quality (a global score of $\leq 5$ ) and poor sleep quality (a global score of $>5$ ) are classified based on the global score.

All PSQI subscales were dichotomize: sleep duration ( $\geq 7$ hours vs $<7$ hours); sleep efficiency ( $\geq 85 \%$ vs $<85 \%$ ); subjective sleep quality (good/fairly good vs bad/very bad); use of sleeping medication (yes vs no); sleep latency ( $\leq 30$ minutes vs $>30$ minutes); sleep disturbances ( $0-9$ vs 10 or more); and daytime dysfunction (yes vs no).

\section{Measures}

A general information questionnaire was used to assess the subjects' demographic information, including gender,

Table I Characteristics of the Subjects $(n=9392)$

\begin{tabular}{|c|c|c|c|c|c|c|}
\hline & $\begin{array}{l}\text { Total } \\
n=9392\end{array}$ & $\begin{array}{l}\text { Elementary } \\
\text { School } \\
n=2912\end{array}$ & $\begin{array}{l}\text { Middle } \\
\text { School } \\
\mathbf{n = 2 8 7 8}\end{array}$ & $\begin{array}{l}\text { High } \\
\text { School } \\
n=2160\end{array}$ & $\begin{array}{l}\text { Vocational High } \\
\text { School } \\
\text { n=720 }\end{array}$ & $\begin{array}{l}\text { University } \\
\mathrm{n}=722\end{array}$ \\
\hline \multicolumn{7}{|l|}{ Grade, $n(\%)$} \\
\hline A & & $968(33.2)$ & $960(33.4)$ & $720(33.3)$ & $240(33.3)$ & $242(33.5)$ \\
\hline B & & $970(33.3)$ & $959(33.3)$ & $720(33.3)$ & $240(33.3)$ & $239(33.1)$ \\
\hline C & & $974(33.4)$ & $959(33.3)$ & $720(33.3)$ & $240(33.3)$ & $24 I(33.4)$ \\
\hline Age (M $\pm S D)$ & $13.80 \pm 2.92$ & $10.53 \pm 1.04$ & $13.35 \pm 1.08$ & $16.08 \pm 1.03$ & $16.48 \pm 1.13$ & $19.25 \pm 1.34$ \\
\hline \multicolumn{7}{|l|}{ Gender } \\
\hline Male & $4914(52.3)$ & $1517(52.1)$ & $1455(50.6)$ & $1223(56.6)$ & $34 I(47.4)$ & $378(52.4)$ \\
\hline Female & $4478(47.7)$ & $1395(47.9)$ & $1423(49.4)$ & $937(43.4)$ & $379(52.6)$ & $344(47.6)$ \\
\hline \multicolumn{7}{|l|}{ Family structure, $n(\%)$} \\
\hline Married & 7791 (83.0) & $2456(84.3)$ & $2350(81.7)$ & $1810(83.8)$ & $526(73.1)$ & $649(89.9)$ \\
\hline Single/widowed & $1601(17.0)$ & $456(15.7)$ & $528(18.3)$ & $350(16.2)$ & $194(26.9)$ & $73(10.1)$ \\
\hline \multicolumn{7}{|l|}{ Family atmosphere, $n(\%)$} \\
\hline Good & $6019(64.1)$ & $194 \mid(66.7)$ & $1775(61.7)$ & $|36|(63.0)$ & $425(59.0)$ & $517(71.6)$ \\
\hline Not good & $3373(35.9)$ & 971 (33.3) & $1103(38.3)$ & $799(37.0)$ & $295(4 I .0)$ & $205(28.4)$ \\
\hline \multicolumn{7}{|l|}{ Academic pressure, $n(\%)$} \\
\hline Big & $1399(14.9)$ & $230(7.9)$ & $526(18.3)$ & $50 I(23.2)$ & $64(8.9)$ & $78(10.8)$ \\
\hline Not big & $7993(85.1)$ & $2682(92.1)$ & $2352(81.7)$ & $1659(76.8)$ & $65.6(91.1)$ & $644(89.2)$ \\
\hline \multicolumn{7}{|l|}{ Friend Number, n(\%) } \\
\hline$\geq 3$ & 7876 (83.9) & $2560(87.9)$ & $2432(84.5)$ & $1739(80.5)$ & $556(77.2)$ & $589(81.6)$ \\
\hline$<3$ & $1516(16.1)$ & $352(12.1)$ & $446(15.5)$ & $421(19.5)$ & $164(22.8)$ & $133(18.4)$ \\
\hline
\end{tabular}

Note: Data presented are $M \pm S D$ or $N(\%)$; $M \pm S D$ is shown for continuous variables.

Abbreviation: $\mathrm{M} \pm \mathrm{SD}$, Mean \pm standard deviation. 
school stage, and grade. Further, in addition to demographic information, other variables that may affect sleep quality were included: family atmosphere, perceived academic pressure, family structure, and number of friends.

\section{Ethics Approval}

This study was reviewed and approved by the Research Ethics Committee of Harbin Medical University.

\section{Statistical Analysis}

To explore the subjects' sleep characteristics, analyses were conducted of the total sample and of each separate school-stage dataset. All variables were examined visually and using descriptive statistics; data were presented as means (standard deviations) for continuous variables and as percentages for discrete variables. Chi-square tests were used to compare PSQI subscales across the school stages. Multivariate logic regression was conducted on the high school sample to explore sleep-related factors for this population. Data were analyzed using SPSS (ver. 20.0). The level of statistical significance was set at $\mathrm{p}<0.05$.

\section{Results}

Tables 1 and 2 summarize the main characteristics of the sample and the results concerning the prevalence of poor sleep quality in participants among the subjects.

Among the five school stages, college students reported the highest proportion of good family atmosphere (71.6\%) and the lowest proportion of single-parent families (10.1\%), while vocational high school students reported the lowest proportion of good family atmosphere (59.0\%) and the highest proportion of single-parent families (26.9\%). Meanwhile, elementary school students reported the highest rate of good self-rated health $(80.5 \%)$, while high school students reported the lowest rate $(54.2 \%)$ in this regard. High school students also reported the highest proportion of perceived academic pressure (23.2\%); vocational high school students (who were of the same age as the high school students) showed a low proportion (8.9\%), but the lowest was among the elementary school students $(7.9 \%)$.

According to the PSQI results, approximately $22.2 \%$ of the sample had poor sleep quality. The overall average PSQI score for all samples was $3.64 \pm 2.81$. However, the prevalence of poor sleep quality varied widely among the different school stages. High school students reported the highest mean PSQI global score $(5.20 \pm 2.86)$, followed by vocational high school $(4.42 \pm 2.93)$, university
(4.21 \pm 2.96$)$, middle school $(3.54 \pm 2.63)$, and elementary school $(2.24 \pm 2.08)$ students. The prevalence of poor sleep quality among elementary school, middle school, high school, vocational high school, and university students were $7.5 \%, 19.2 \%, 41.9 \%, 28.6 \%$ and $28.5 \%$, respectively. Figure 1 shows the box plot of PSQI global scores for students at five school stages.

Significant school-stage effects were also found for sleep duration, sleep efficiency, subjective sleep quality, sleep medication use, sleep latency, disturbances, and daytime dysfunction (Table 2). According to the result for the PSQI subscales (Table 2), all school stages showed high proportions of shorter sleep duration and day dysfunction, but these were especially high among high school students: high school students reported the highest prevalence of short sleep duration (70.8\%), subjective bad sleep quality (17.2\%), and day dysfunction (84.7\%). Meanwhile, elementary school students showed the highest prevalence of poor sleep efficiency (17.9\%), followed by vocational high school students $(17.8 \%)$. College students reported the highest prevalence of sleep medication use (6.4\%). Vocational high school students showed the highest prevalence of sleep latency (6.3\%) and sleep disturbance (7.4\%).

As the high school students reported the worst sleep quality, multivariate logistic regression analysis was conducted on these subjects' responses. The logistic regression model consequently indicated that high school students who feel greater academic pressure $(\mathrm{OR}=$ $2.595,95 \% \mathrm{CI}=2.101-3.206$ ), those with a poor family atmosphere $(\mathrm{OR}=2.501,95 \% \mathrm{CI}=2.067-3.027)$, and those who have fewer friends $(\mathrm{OR}=1.490,95 \% \mathrm{CI}=$ $1.190-1.865)$ tended to reported poor sleep quality. In addition, the students in grade 3 were more likely to report poor sleep $(\mathrm{OR}=1.340,95 \% \mathrm{CI}=1.074-1.671)$ than those in grade 1 (Table 3).

\section{Discussion}

Students show the unique effects of sleep problems. Sleep problems have long been common among Chinese students. ${ }^{24}$ However, while most studies have focused on the effect of changes in age on sleep, little attention has been given to students' sleep at different school stages. The current study explored sleep quality and various dimensions of the sleep (sleep duration, sleep efficiency, subjective sleep quality, sleep medication use, sleep latency, disturbances, and daytime dysfunction), as well as factors associated with sleep quality. 
Table 2 Global Score and Subscales of PSQI from Elementary School to University

\begin{tabular}{|c|c|c|c|c|c|c|c|}
\hline & $\begin{array}{l}\text { Total } \\
n=9392\end{array}$ & $\begin{array}{l}\text { Elementary } \\
\text { School } \\
n=2912\end{array}$ & $\begin{array}{l}\text { Middle } \\
\text { School } \\
n=2878\end{array}$ & $\begin{array}{l}\text { High } \\
\text { School } \\
n=2160\end{array}$ & $\begin{array}{l}\text { Vocational High } \\
\text { School } \\
n=720\end{array}$ & $\begin{array}{l}\text { University } \\
\mathrm{n}=722\end{array}$ & $\chi^{2} / F$ \\
\hline \multicolumn{8}{|l|}{ Global score of PSQI } \\
\hline PSQI, (M $\pm S D)$ & $3.64 \pm 2.81$ & $2.24 \pm 2.08$ & $3.54 \pm 2.63$ & $5.20 \pm 2.86$ & $4.42 \pm 2.93$ & $4.21 \pm 2.96$ & $438.580 * * *$ \\
\hline $\begin{array}{l}\text { PSQI, n(\%) } \\
\quad \leq 5 \\
>5\end{array}$ & $\begin{array}{l}7306(77.8) \\
2086(22.2)\end{array}$ & $\begin{array}{l}2694(92.5) \\
218(7.5)\end{array}$ & $\begin{array}{l}2326(80.8) \\
552(19.2)\end{array}$ & $\begin{array}{l}1256(58.1) \\
904(41.9)\end{array}$ & $\begin{array}{l}5 \mid 4(7 \mid .4) \\
206(28.6)\end{array}$ & $\begin{array}{l}516(7 \mid .5) \\
206(28.5)\end{array}$ & $896.780 * * *$ \\
\hline \multicolumn{8}{|l|}{ Subscales of PSQI } \\
\hline Duration, $(M \pm S D)$ & $7.95 \pm 1.46$ & $9.03 \pm 1.19$ & $7.97 \pm 1.23$ & $6.86 \pm 1.14$ & $7.52 \pm 1.33$ & $7.25 \pm 1.13$ & $696.749 * * *$ \\
\hline $\begin{array}{l}\text { Duration, } \mathrm{n}(\%) \\
\quad \geq 7 \mathrm{~h} \\
<7 \mathrm{~h}\end{array}$ & $\begin{array}{l}6053(64.4) \\
3339(35.6)\end{array}$ & $\begin{array}{l}26 I I(89.7) \\
30 I(10.3)\end{array}$ & $\begin{array}{l}2049(71.2) \\
829(28.8)\end{array}$ & $\begin{array}{l}63 \mid(29.2) \\
1529(70.8)\end{array}$ & $\begin{array}{l}430(59.7) \\
290(40.3)\end{array}$ & $\begin{array}{l}332(46.0) \\
390(54.0)\end{array}$ & $2150.112^{* * * *}$ \\
\hline $\begin{array}{l}\text { Efficiency, } n(\%) \\
\qquad 885 \% \\
\quad<85 \%\end{array}$ & $\begin{array}{l}7970(84.9) \\
1422(15.1)\end{array}$ & $\begin{array}{l}2392(82.1) \\
520(17.9)\end{array}$ & $\begin{array}{l}2522(87.6) \\
356(12.4)\end{array}$ & $\begin{array}{l}1865(86.3) \\
295(13.7)\end{array}$ & $\begin{array}{l}592(82.2) \\
128(17.8)\end{array}$ & $\begin{array}{l}599(82.9) \\
123(17.0)\end{array}$ & $43.539 * * *$ \\
\hline $\begin{array}{l}\text { Subjective sleep quality, } \\
n(\%) \\
\text { good } \\
\text { bad/very bad }\end{array}$ & $\begin{array}{l}8373(89.2) \\
1019(10.8)\end{array}$ & $\begin{array}{l}2752(94.5) \\
160(5.5)\end{array}$ & $\begin{array}{l}2568(89.2) \\
310(10.8)\end{array}$ & $\begin{array}{l}\mid 789(82.8) \\
37 \mid(17.2)\end{array}$ & $\begin{array}{l}615(85.4) \\
105(14.6)\end{array}$ & $\begin{array}{l}649(89.9) \\
73(10.1)\end{array}$ & $|86.5| 3^{* * *}$ \\
\hline $\begin{array}{l}\text { Use of medication, } \mathrm{n}(\%) \\
\text { No } \\
\text { Yes } \\
\text { Sleep latency, (minutes) }\end{array}$ & $\begin{array}{l}9122(97.1) \\
270(2.9) \\
14.97 \pm 11.76\end{array}$ & $\begin{array}{l}2865(98.4) \\
47(1.6) \\
13.73 \pm 10.45\end{array}$ & $\begin{array}{l}2805(97.5) \\
73(2.5) \\
|4.90 \pm||.7|\end{array}$ & $\begin{array}{l}2087(96.6) \\
73(3.4) \\
15.28 \pm \mid 1.8\end{array}$ & $\begin{array}{l}688(95.6) \\
32(4.4) \\
17.93 \pm 13.87\end{array}$ & $\begin{array}{l}677(93.8) \\
45(6.2) \\
16.33 \pm 13.44\end{array}$ & $\begin{array}{l}55.239 * * * \\
416.436 * * *\end{array}$ \\
\hline $\begin{array}{l}\text { Sleep latency, } \mathrm{n}(\%) \\
\quad \leq 30 \text { minutes } \\
>30 \text { minutes }\end{array}$ & $\begin{array}{l}9048(96.3) \\
344(3.7)\end{array}$ & $\begin{array}{l}2842(97.6) \\
70(2.4)\end{array}$ & $\begin{array}{l}277 \mid(96.3) \\
107(3.7)\end{array}$ & $\begin{array}{l}2077(96.2) \\
83(3.8)\end{array}$ & $\begin{array}{l}675(93.8) \\
45(6.3)\end{array}$ & $\begin{array}{l}683(94.6) \\
39(5.4)\end{array}$ & $33.148 * * *$ \\
\hline $\begin{array}{l}\text { Disturbance, } n(\%) \\
\text { score }<10 \\
\text { score } \geq 10\end{array}$ & $\begin{array}{l}886 \mid(94.3) \\
53 \mid(5.7)\end{array}$ & $\begin{array}{l}2800(96.2) \\
112(3.8)\end{array}$ & $\begin{array}{l}27 \mid 3(94.3) \\
165(5.7)\end{array}$ & $\begin{array}{l}2005(92.8) \\
155(7.2)\end{array}$ & $\begin{array}{l}667(92.6) \\
53(7.4)\end{array}$ & $\begin{array}{l}676(93.6) \\
46(6.4)\end{array}$ & $31.886 * * *$ \\
\hline $\begin{array}{l}\text { Day dysfunction, } n(\%) \\
\text { No } \\
\text { Yes }\end{array}$ & $\begin{array}{l}3629(38.6) \\
5763(61.4)\end{array}$ & $\begin{array}{l}1949(66.9) \\
963(33.1)\end{array}$ & $\begin{array}{l}935(32.5) \\
1943(67.5)\end{array}$ & $\begin{array}{l}331(15.3) \\
1829(84.7)\end{array}$ & $\begin{array}{l}192(26.7) \\
528(73.3)\end{array}$ & $\begin{array}{l}222(30.7) \\
500(69.3)\end{array}$ & $1586.674^{* * *}$ \\
\hline
\end{tabular}

Notes: Data presented are $M \pm S D$ or $N(\%) ; M \pm S D$ is shown for continuous variables; $* * * P<0.001$.

Abbreviations: $M \pm S D$, Mean \pm standard deviation; PSQI, Pittsburgh Sleep Quality Index; $h$, hours.

\section{Sleep Status at Different School Stages}

Our findings clearly demonstrate that the quality and characteristics of sleep vary greatly among students at different school stages, with significant school-stage effects being found for sleep quality on school nights.

Across all school stages, elementary school students showed the lowest prevalence of poor sleep quality (7.5\%). In this study, the average sleep duration (for elementary school grades 4,5 , and 6) on weekdays was 9.03 hours, which is longer than those reported in previous studies conducted in
Japanese ( 8.57 hours for grade 4; 8.30 hours for grade 5; and 8.08 hours for grade 6) and Korean (overall average: 8.18 hours). ${ }^{8,13}$ In the present sample, the most prominent sleep problem among elementary students was low sleep efficiency.

Middle school and high school are critical transitional stages characterized by a plethora of physical, psychological, and cognitive changes. ${ }^{24,25}$ It has long been the case that Asian adolescents, including those in China, receive relatively large amounts of homework and spend longer periods of time learning than their American and European peers. They go to 


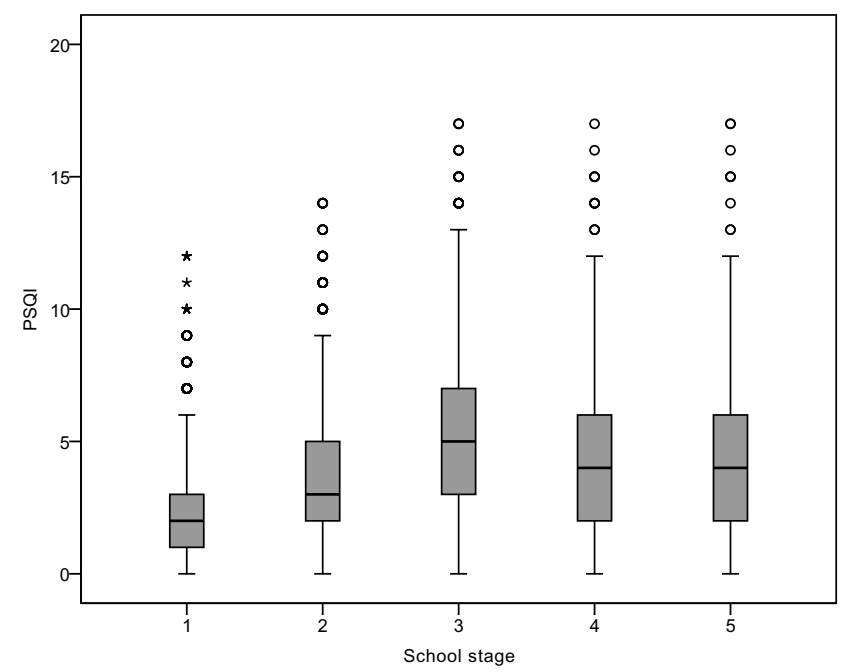

Figure I The global scores of PSQI for students at five school stages. I Elementary school. 2 Middle school. 3 High school. 4 Vocational high school. 5 University. The "o" represents "outlier", the "*” represents "extreme".

bed later than North American adolescents and obtain less sleep than European samples, partly as a result of their rigid school schedules and intense academic and social demands; they also tend to report higher rates of daytime sleepiness. ${ }^{21,26}$ When students enter the middle school stage, they are in the midst of a series of changes. The onset of puberty coincides with increased expectations regarding academic performance and a desire for independence from parents and teachers, all of which can create challenges. In addition, Chinese middle school students spend a considerable amount of time on academic works in order to prepare for their forthcoming high school entrance examination, because they believe that entering a high-quality high school can double their chances of entering a high-level university.

Among the five school stages, high school students showed the highest prevalence of poor sleep quality
$(41.9 \%)$ and poor subjective sleep quality $(17.2 \%)$, and reported extremely high rates of short sleep duration (70.8\%) and day dysfunction (84.7\%). Notably, the sleep problems of high school students are much more serious than those of vocational high school students. In China, high school and vocational high school are all the next school stage (high school stage) after middle school stage, but their school types and learning tasks are extraordinarily different. Most vocational high school students begin working immediately after graduation; however, high school students' main objective is to enter a competitive university and pursue further study. In this study, the age structures of the high school $(16.08 \pm 1.03)$ and vocational high school (16.48 \pm 1.13$)$ students were similar; however, their sleep patterns varied greatly as a result of the different educational pressures and academic burdens they experienced. It is not unusual for high school students to spend long periods studying to gain entry to China's extremely competitive university system. ${ }^{10}$ In this study, the prevalence of poor sleep quality among the vocational high school students was much lower than that of the high school students, but the vocational high school students reported the highest prevalence of long sleep latency and disturbance, and the second-highest prevalence of daytime dysfunction. This may be related to the lower academic pressure and the higher proportion of accommodation (52.2\% for vocational high school students and $22.5 \%$ for high school students, data are not showed in the Table) of vocational high school students, which create a lack of parental supervision, and also allows vocational high school students more time to use screens before falling asleep. Indeed, just $8.9 \%$ of the vocational college students reported perceiving a high level of academic pressure; slightly higher than the elementary school

Table 3 Risk Factors for Poor Sleep Quality (Global Score of PSQI >5) Identified by Logistic Regression Analysis of High School Students

\begin{tabular}{|c|c|c|c|c|c|c|}
\hline & $\boldsymbol{\beta}$ & S.E & Wald & $\mathbf{P}$ & OR & $95 \% \mathrm{Cl}$ \\
\hline \multicolumn{7}{|l|}{ Grade(I-ref) } \\
\hline 2 & 0.068 & 0.113 & 0.365 & 0.546 & I.07। & $0.858-1.336$ \\
\hline 3 & 0.293 & 0.113 & 6.742 & $0.009 * *$ & 1.340 & $|.074-1.67|$ \\
\hline Gender (Male-ref) & -0.025 & 0.093 & 0.072 & 0.788 & 0.975 & $0.813-1.170$ \\
\hline Family structure (married-ref) & -0.205 & 0.128 & 2.580 & 0.108 & 0.815 & $0.634-1.046$ \\
\hline Family atmosphere (bad-ref) & 0.917 & 0.097 & 88.712 & $0.000 * * *$ & 2.501 & $2.067-3.027$ \\
\hline Academic pressure (big-ref) & 0.954 & 0.108 & 78.264 & $0.000^{* * *}$ & 2.595 & $2.10 \mathrm{I}-3.206$ \\
\hline Friend Number (<3-ref) & 0.399 & 0.115 & 12.079 & $0.001 * *$ & 1.490 & $1.190-1.865$ \\
\hline
\end{tabular}

Note: $* * \mathrm{P}<0.01$; ***P $<0.001$.

Abbreviations: $\mathrm{Cl}$, confidence interval; $\mathrm{OR}$, odds ratio. 
students $(7.95 \%)$; however, the proportion of high school students who perceived a high level of academic pressure was $23.2 \%$. Widespread reports of sleep deprivation among adolescents have resulted in an increased focus on the general sleep problems experienced by high school students. Insufficient sleep is especially problematic for high school students who place a heavy emphasis on academic achievement, ${ }^{10,27}$ as students and their parents generally believe that it is worthwhile to curtail sleep in order to pursue better academic-performance objectives. Their rigid school schedules and intense academic and social demands exacerbate existing sleep problems, and many of these problems tend to increase across high school years.

In our sample, the prevalence of poor sleep quality increased as the school stage increased, reaching the highest level in high school (41.9\%) and vocational high school $(28.6 \%)$; however, it then declined in the university stage $(28.5 \%)$, where academic pressure is relatively lower. Despite this, sleep problems in college cannot be ignored. The numerous health and academic-related consequences of sleep problems make sleep, particularly during emerging adulthood, a public health concern. ${ }^{14}$ College students experience unique challenges at the beginning of campus life (eg experiencing an unfamiliar environment, being responsible for oneself for the first time, academic stress, and living in a dormitory with students from different regions and cultures), all of which influence, or even heavily change, their sleep styles and sleep quality. The prevalence of poor sleep quality and the average PSQI score in our study were similar to those reported in previous studies of Chinese college students. ${ }^{28}$ Notably, in the comparison of the five school stages, the outstanding problem for college students was a high rate of sleep medication use.

\section{Meaningful Factors for Sleep Quality}

Although sleep characteristics are, to a certain extent, determined individually, this study demonstrates that Chinese students' sleep is affected by their school stages. In addition to the school-stage factor, however, we further analyzed the relationship between sleep and certain other factors in order to learn more about the factors that affect sleep at the high school stage. In this study, the meaningful variables regarding sleep quality at the high school stage were determined to be self-rated academic pressure, family atmosphere, number of friends, and grade.
Among the five school stages, the high school sample showed the highest level of self-rated academic pressure. Good results in examinations can bring rich returns, such as a lucrative career and good teacher-student and parentchild relationships. In particular, such success can have a profound impact on cultures that value education. ${ }^{29}$ China's large population means the academic environment for Chinese students is highly competitive. ${ }^{30}$ To some extent, adolescents and young adults are more strongly influenced by pressure than older adults. For Chinese students, the high level of academic pressure applied by school teachers, parents, and even themselves has been found to cause them to experience more sleep problems than their western counterparts. ${ }^{21}$ A previous study of sleep problems among Chinese adolescents from Taiwan found that students with high academic stress are more likely to have sleep problems than are students with low academic stress who take similar tests. ${ }^{31}$ This effect has also been found in other Asian countries that place a strong focus on academic performance, such as South Korea. ${ }^{8}$ Stress is intimately associated with shorter sleep, sleep-onset latency, and lower sleep efficiency. ${ }^{32}$ Moreover, in addition to its huge impact on sleep, academic pressure may also lead to lifelong emotional dysfunction.

Sleep quality is a multidimensional construct that can be influenced by interpersonal relationships; good interpersonal relationships can positively contribute to sleep quality. ${ }^{33}$ In this study, having a good family atmosphere and more friends were found to contribute to good sleep quality. For high school students with high academic pressure, family represents a crucial source of support and emotional security. Intimate interpersonal relationships can foster perceptions of safety and support and can positively affect mood and anxiety, which can potentially impact sleep. A previous study of a large sample of adolescents aged 11-15 years showed that a positive family atmosphere is the main factor predicting high-quality sleep, and this finding remained true irrespective of gender and age. ${ }^{34}$ Another study of 763 16-year-old students also found that sleep problems are closely related to poor family environment. ${ }^{35}$ These studies findings show that, for adolescents, family atmosphere is associated with sleep quality. Thus, family atmosphere can be considered as a protective factor that fosters resilient adaptation among students, particularly if they are exposed to stressful circumstances. ${ }^{36}$ However, no effect of parents' marital status on sleep quality has been found; this may be 
because parents' marital status does not necessarily influence the parent-child relationship and, thus, does not seriously affect sleep. The sense of security necessary for quality sleep comes from a good interpersonal environment. $^{37}$ Peer relationships are very prominent for students; peer-related problems can trouble young people, which can disturb their sleep. Peers are an important part of students' social lives; high school students' academic and extra-curricular activities frequently involve interactions with other teenagers, meaning peer relationships are ubiquitous. Positive peer relationships may contribute to better sleep, as students with such good relationships may be less likely to experience arousal, pain, or concerns that may interfere with sleep. Similar results have also been found among college students: the higher the quality of college students' friendships, the better their sleep quality. $^{38}$

Sleep quality can also be affected by grade. In this study, grade was found to affect the sleep quality of the high school students. There was no significant difference in this regard between the 1st and 2nd-grade high school students, but the 3rd-grade students were significantly more likely to report poor sleep quality than were the 1stgrade students. This phenomenon could be related to the fact that the 3rd-grade students spend most of their final high school year preparing for China's strict National College Entrance Exam. A previous study of high school students in the United States found that older students have the most severe sleep deprivation throughout high school. ${ }^{39}$ Similar results were reported in a recent study conducted in Brazil, where the prevalence of inadequate sleep among high school students was found to increase with grade: from $51.7 \%$ in the 1 st grade to $60.7 \%$ in the 3rd grade. ${ }^{40}$

Sleep is an important healthy behavior, which can affect the body and cognitive function extensively. ${ }^{41}$ Adolescent behavioral habits, including sleep, tend to persist into adulthood. ${ }^{14}$ However, high school students in China are among the most sleep-restricted population. Despite the increasing evidence of the detrimental effects of sleep loss in students, little has considered their exact school stages as modifiers of sleep patterns. This study examined sleep quality in students of northeast China. Due to different ages, physical and mental development and academic performance expectations, we found that sleep characteristics differed among students from elementary school to university, this may suggest that the stages of school and the deeper implications associated with it may play important roles in determining whether adolescents can achieve quality sleep. Previous studies indicate that older age was associated with shorter sleep within school-aged children and adolescents. ${ }^{42}$ In this study, according to the sleep characteristics of high school students and vocational high school students, it is shown that their sleep quality varies greatly due to different environment and learning goals even if their similar age structure.

The primary strength of this study is its use of a multischool-stage measurement of sleep quality. However, there are some limitations that must be acknowledged. First, the use of a cross-sectional survey limited causal inference. Second, in addition to the factors found in this study, sleep quality may also be affected by many other complex factors, such as the use of electronic light-emitting products before sleep. Third, adopting 7 hours as the cutoff for the best sleep duration may underestimate the proportion of poor sleep quality for the elementary school sample. Indeed, sleep patterns, including appropriate sleep durations, change throughout life, and are influenced by age and various other factors. However, by consulting the literature it was determined that, in addition to its extensive use among samples of adults and adolescents, ${ }^{43}$ the PSQI has also been widely used among children/elementary school students in China and other countries. ${ }^{4-53}$ In this study, the main function of PSQI measurement in elementary school students is to compare multiple sleep characteristics among different school stages through seven subscales, and to obtain data that could also provide some reference for future research. Meanwhile, there is currently no unified and authoritative standard regarding the reasonable sleep durations for different age groups, and this scale was considered indispensable for the present study. Finally, the need for sleep is known to differ strongly between individuals and the debate on what constitutes "optimal sleep" is still ongoing.

\section{Conclusions}

Among students, sleep patterns from childhood to early adulthood are related not only to chronologic age but also to school stage. We found that school stage may play an important role in determining whether students secure high-quality sleep. Differences in sleep duration, variability, and patterns exist within school stages. In addition, the high prevalence of poor sleep quality among high school students indicates that high school students should 
urgently be informed of the importance of adequate sleep and the consequences of inadequate sleep.

\section{Abbreviations}

PSQI, Pittsburgh Sleep Quality Index.

\section{Acknowledgments}

This study was supported by the National Social Science Foundation of China (Grant No. 19AZD013). The authors would like to express our appreciation to all of the individuals for their involvement in the study, including each of the school teachers and students for their support during the data collection.

\section{Disclosure}

The authors declared that they have no conflicts of interest for this work.

\section{References}

1. Iemura A, Iwasaki M, Yamakawa N. Influence of sleep-onset time on the development of 18-month-old infants: japan Children's cohort study. Brain Dev. 2016;38:364-372. doi:10.1016/j.braindev.2015. 10.003

2. Wang X, Gao X, Yang Q. Sleep disorders and allergic diseases in Chinese toddlers. Sleep Med. 2017;37:174-179. doi:10.1016/j. sleep.2017.02.011

3. Hurtley SM. Sleep and Alzheimer's Disease. Sleep Medcine Rev. 2015;19(1):29-38. doi:10.1016/j.smrv.2014.03.007

4. D A B, Chokroverty S. Neurologic diseases and sleep. Sleep Med Clin. 2017;12(1):73-85. doi:10.1016/j.jsmc.2016.10.007

5. Pooja BM. Sleep duration is a significant predictor of cardiac autonomic neuropathy in type 2 diabetes mellitus. Prim Care Diab. 2019;13(5):452-461. doi:10.1016/j.pcd.2019.02.002

6. I J B, A J O, Rosmalen JGM. Sleep problems and pain. Pain. 2016;157(4):957-963. doi:10.1097/j.pain.0000000000000466

7. D R J K A, N D J S, Carmo C. The impact of sleep quality on the mental health of a non-clinical population. Sleep Med. 2018; S1389945718300698.

8. C K Y, J K K, Patel SR. Age-related changes in sleep/wake patterns among korean teenagers. Pediatrics. 2005;115(1):250-256. doi:10. 1542/peds.2004-0815G

9. J F D, A M M, Oort FJ. The influence of sleep quality, sleep duration and sleepiness on school performance in children and adolescents: A meta-analytic review. Sleep Med Rev. 2010;14(3):0-189.

10. S C Y, A M J, Erwin C. Associations of sleep duration on school nights with self-rated health, overweight, and depression symptoms in adolescents: problems and possible solutions. Sleep Med. 2018.

11. A I C, C A Y, Richardson CG. Chronic sleep disturbance, not chronic sleep deprivation, is associated with self-rated health in adolescents. Prev Med. 2019;124:11-16. doi:10.1016/j.ypmed.2019.04.014

12. Li A, Chen S, Quan SF. Sleep patterns and sleep deprivation recorded by actigraphy in 4th-grade and 5th-grade students. Sleep Med. 2019;67:191-199. doi:10.1016/j.sleep.2019.12.001

13. Naoko S, David G, Smith DL. Sleep duration, snoring prevalence, obesity, and behavioral problems in a large cohort of primary school students in Japan. Sleep. 3:3.
14. J G P, O’Brien F, Haynie DL. Adolescent sleep insufficiency one year after high school. J Adolesc. 2018;68:165-170. doi:10.1016/j. adolescence.2018.07.016

15. Liu X, Buysse DJ. Sleep and youth suicidal behavior: a neglected field. Curr Opin Psychiatry. 2006;19(3):288-293. doi:10.1097/01. yco.0000218600.40593.18

16. Li L, K I L, Mei SL. Sleep duration and self-rated health in Chinese university students. Sleep Breathing. 2019;23:1351-1356. doi:10.10 07/s11325-019-01856-w

17. Jin Y, Ding Z, Fei Y. Social relationships play a role in sleep status in Chinese undergraduate students. Psychiatry Res. 2014;220 (12):631-638. doi:10.1016/j.psychres.2014.08.029

18. Suhaib K, S T A, Ariana H. Onset insomnia and insufficient sleep duration are associated with suicide ideation in university students and athletes. J Affect Disord. 2020;S01650327(20)30120-8.

19. S P B, M A J, Luebbe AM. Sleep in a large, multi-university sample of college students: sleep problem prevalence, sex differences, and mental health correlates. Sleep Health. 2018;S2352721818300068.

20. J J M-V, J M M-S, Bruno R. Age and gender effects on the prevalence of poor sleep quality in the adult. Gac Sanit. 2017;31 (1):18-22. doi:10.1016/j.gaceta.2016.05.013

21. Gradisar M, Gardner G, Dohnt H. Recent worldwide sleep patterns and problems during adolescence: A review and meta-analysis of age, region, and sleep. Sleep Med. 2011;12(2):0-118. doi:10.1016/j.sleep.2010.11.008

22. Liu X, Tang M, Hu L. Reliability and validity of the Pittsburgh sleep quality index. Chinese J Psychiatry. 1996;29(2):103-107.

23. R T H H, Fong TCT. Factor structure of the Chinese version of the pittsburgh sleep quality index in breast cancer patients. Sleep Med. 2014;15(5):565-569. doi:10.1016/j.sleep.2013.10.019

24. Q H G, Li H, Zhang XH. Associations between sleep duration and physical activity and dietary behaviors in Chinese adolescents: results from the youth behavioral risk factor surveys of 2015. Sleep Med. 2017;37:168-173. doi:10.1016/j.sleep.2017.06.024

25. S X L, N Y C, Man YMW. Eveningness chronotype, insomnia symptoms, and emotional and behavioural problems in adolescents. Sleep Med. 2018;47:93-99. doi:10.1016/j.sleep.2018.03.025

26. Wang N, He J, Wang Z. The prevalence of sufficient physical activity among primary and high school students in Mainland China: a systematic review and meta-analysis. Public Health. 2018;163:67-75. doi:10.1016/j.puhe.2018.06.019

27. Xiong W, Liu H, Gong P. Relationships of coping styles and sleep quality with anxiety symptoms among Chinese adolescents: a cross-sectional study. J Affect Disord. 2019;257.

28. Wang L, Qin P, Zhao Y. Prevalence and risk factors of poor sleep quality among Inner Mongolia Medical University students: a cross-sectional survey. Psychiatry Res. 2016;244:243-248. doi:10.1016/j.psychres.2016.04.011

29. Rui Y. Self and the other in the Confucian cultural context: implications of China's higher education development for comparative studies. Int Rev Education. 2011;57(3):337-355. doi:10.1007/s11159-011-9208-x

30. Li H. The 'secrets' of Chinese students' academic success: academic resilience among students from highly competitive academic environments. Educational Psychol. 2017;37:1001-1014. doi:10.1080/ 01443410.2017 .1322179

31. T Y C, Y C C, Tzeng NS. Effects of a selective educational system on fatigue, sleep problems, daytime sleepiness, and depression among senior high school adolescents in Taiwan. Neuropsychiatr Dis Treat. 2015;11:741-750.

32. Svetlana M, Amy C, Nicholas B. Sleep and stress in adolescents: the roles of pre-sleep arousal and coping during school and vacation. Sleep Med. 2020;66:130-138. doi:10.1016/j. sleep.2019.10.006

33. H E G, W M T, Hall MH. Interpersonal distress is associated with sleep and arousal in insomnia and good sleepers. J Psychosom Res. 2014;76(3):242-248. doi:10.1016/j.jpsychores.2013.11.010 
34. Jorma T, Lasse K, Esk L. Perceived sleep quality and its precursors in adolescents. Health Promot Int. 1999;14(2):155-166. doi:10.1093/ heapro/14.2.155

35. Vignau J, Bailly D, Duhamel A. Epidemiologic study of sleep quality and troubles in French secondary school adolescents. J Adolescent Health Official Publication Society Adolescent Med. 1997;21(5):343. doi:10.1016/S1054-139X(97)00109-2

36. Bajoghli H, Alipouri A, Holsboer-Trachsle E. Sleep patterns and psychological functioning in families in northeastern Iran; evidence for similarities between adolescent children and their parents. $J$ Adolesc. 2013;36 (6):1103-1113. doi:10.1016/j.adolescence.2013.08.016

37. R E D, Lewin DS. Pathways to adolescent health sleep regulation and behavior. J Adolescent Health. 2002;31(6):175-184. doi:10.1016/ S1054-139X(02)00506-2

38. Tavernier R, Willoughby T. Bidirectional associations between sleep (quality and duration) and psychosocial functioning across the university years. Dev Psychol. 2014;50(3):674-682. doi:10.1037/ a0034258

39. D K E, L R M-E, Lowry R. Prevalence of insufficient, borderline, and optimal hours of sleep among high school students United States, 2007. J Adolescent Health Official Publication Society Adolescent Med. 2010;46(4):399-401. doi:10.1016/j.jadohealth.2009.10.011

40. Alves FR, de Souza EA, Ferreira LGDF. Sleep duration and daytime sleepiness in a large sample of Brazilian high school adolescents. Sleep Med. 2020;66:207-215. doi:10.1016/j.sleep.2019.08.019

41. E J B, C V R, Staaks J. Effects of sleep manipulation on cognitive functioning of adolescents: a systematic review. Sleep Med Rev. 2017;32:45-57. doi:10.1016/j.smrv.2016.02.006

42. M O M, A C M, Christian G. Meta-analysis of quantitative sleep parameters from childhood to old age in healthy individuals: developing normative sleep values across the human lifespan. Sleep. 2004;27(7):1255-1273. doi:10.1093/sleep/27.7.1255

43. Mariman A, Vogelaers D, Hanoulle I, et al. Validation of the three-factor model of the PSQI in a large sample of chronic fatigue syndrome (CFS) patients. J Psychosom Res. 2012;72(2):111-113. doi:10.1016/j.jpsychores.2011.11.004
44. Chen F, Wei N, Ma C. Investigation on the sleep problems in children with attention deficit/hyperactivity disorder. Chinese J Child Health Care. 2020;(5):6-9. In Chinese.

45. Yong N, Wang H, Hu H. Relationship among child-abuse, depressive symptoms and sleep quality in grade 46 primary students. Chinese Mental Health J. 2011;25(8):616-621.

46. Liu H, Shang L, Chen J. Current situation of sleep snoring in primary school students in xi'an and its impact on quality of life. Chinese J Child Health Care. 2019;(9):1030-1033. In Chinese.

47. Li H, Liu C, Qiu Q. Investigative Study on Grade 4 6 Pupils'Sleep Status in a County of Qingyang. Chinese Primary Health Care. 2017;31(10):72-74.

48. Yong $\mathrm{N}$, Wang $\mathrm{H}, \mathrm{Hu} \mathrm{H}$. Sleep quality and its influencing factors among primary students in Chongqing city. Chinese J Public Health. 2012;(6):727-730. In Chinese.

49. D M N, T A W, Cox J. Catastrophizing and poor sleep quality in early adolescent females. Behav Sleep Med. 2014;12(1):41-52. doi:10. 1080/15402002.2013.764528

50. Demirci E. Non suicidal self-injury, emotional eating and insomnia after child sexual abuse: are those symptoms related to emotion regulation? J Forensic Leg Med. 2018;53:17-21. doi:10.1016/j. jflm.2017.10.012

51. Ertan P, Yilmaz O, Caglayan M. Relationship of sleep quality and quality of life in children with monosymptomatic enuresis. Child Care Health Dev. 2010;35(4):469-474.

52. Yuksel H, Sogut A, Yilmaz O. Evaluation of sleep quality and anxiety-depression parameters in asthmatic children and their mothers. Respir Med. 2007;101(12):2550-2554. doi:10.1016/j. rmed.2007.07.025

53. Baran TR, Müge A. Restless legs syndrome and poor sleep quality in obese children and adolescents. J Clin Res Pediatr Endocrinol. 2018;10(2):131-138. doi:10.4274/jcrpe.5165

\section{Publish your work in this journal}

Nature and Science of Sleep is an international, peer-reviewed, open access journal covering all aspects of sleep science and sleep medicine, including the neurophysiology and functions of sleep, the genetics of sleep, sleep and society, biological rhythms, dreaming, sleep disorders and therapy, and strategies to optimize healthy sleep.
The manuscript management system is completely online and includes a very quick and fair peer-review system, which is all easy to use. Visit http://www.dovepress.com/testimonials.php to read real quotes from published authors. 